\title{
PLACENTA ACCRETA IN PRIMIGRAVIDA AT PERIPHERAL SETUP - A RARE CASE REPORT
}

\author{
NIRAJ CHOUREY ${ }^{1 *}$, HIREMATH RN² ${ }^{\text {, MANPAL SINGH YADAV }}{ }^{3}$, SANDHYA GHODKE ${ }^{4}$, DOBI SRAVAN KUMAR ${ }^{5}$
}

${ }^{1}$ Obstetrician, Babina, Uttar Pradesh, India. ${ }^{2}$ Public Health Specialist, Bengaluru, Karnataka, India. ${ }^{3}$ Anaesthetist, Babina, Uttar Pradesh, India. ${ }^{4}$ Anaesthetist, Rainbow Children's Hospital, Bangalore, India. ${ }^{5}$ Medical officer, Delhi, India. Email: hansineer@gmail.com

Received: 19 May 2021, Revised and Accepted: 05 June 2021

ABSTRACT

One of the risk factors for maternal mortality is morbidly adherent placenta (MAP) and accounts for 7-10\% of maternal mortality cases worldwide. Placenta accreta is the most common type of MAP, while the other two types are placenta increta and placenta percreta. Placenta accrete accounts for $75-80 \%$ of MAP. Here, we present a case of 22 years old, primigravida with no known antenatal risk factors, diagnosed to have placenta accreta intraoperatively after delivering health baby. It is extremely rare for MAP to occur in a patient with no prior risk factors in a primigravida. Peripartum hysterectomy is the only option in a limited care facility with a hemodynamically unstable patient without a proper full-fledged blood bank facility. It is once again reiterated that bleeding from the vagina that does not slow or stop, drop in blood pressure and signs of shock are early signs of blood loss and should be investigated with great concern.

Keywords: Placenta Accreta, Primigravida, Morbidly adherent placenta.

(c) 2021 The Authors. Published by Innovare Academic Sciences Pvt Ltd. This is an open access article under the CC BY license (http://creativecommons.org/ licenses/by/4.0/) DOI: http://dx.doi.org/10.22159/ajpcr.2021v14i6.42115. Journal homepage: https://innovareacademics.in/journals/index.php/ajpcr

\section{INTRODUCTION}

One of the risk factors for maternal mortality is morbidly adherent placenta (MAP) and accounts for $15 \%$ of all cases who present with obstetrical bleeding and subsequently receive blood transfusion and accounts for $7-10 \%$ of maternal mortality cases worldwide [1]. MAP is usually seen in high-risk women with placenta previa, secondtrimester serum levels of AFP and free $\beta$-hCG greater than 2.5 multiples of median [2], two or more cesarean deliveries [3], previous uterine surgery, previous uterine curettage, maternal age $\geq 35$ years, multiparity, and high gravidity [4]. According to depth of invasion, MAP can be divided into three types. Placenta accrete accounts for 75-80\% of MAP [5], while other two types are less common and more severe form of MAP (placenta percreta and placenta increta).

When chorionic villi gets abnormally attached to myometrium rather than being restricted within the decidua, then it is called placenta accreta (Fig. 1). When chorionic villi get abnormally invaded into the myometrium, then it is called placenta increta. When chorionic villi get abnormally invaded through the myometrium and involve bladder in many cases, then it is called placenta percreta. Increased risk of heavy bleeding is seen in placenta accrete at the time of attempted placental delivery due to abnormal attachment to myometrium, requiring urgent and frequent blood transfusion and hysterectomy in-case bleeding is not controlled to save the life of patient. Placenta accrete is associated with lots of complications which include local organs damage and damage to neurovascular structures in retroperitoneum and lateral pelvic walls from placental implantation and its removal, post-operative bleeding requiring repeated surgery, amniotic fluid embolism, and coagulation complications due to massive bleeding and transfusion of blood/blood products and later on can lead to infection, multiorgan failure, and maternal death $[6,7]$.

Although the exact incidence of maternal mortality related to placenta accreta and its complications is unknown, but in few case series and studies it is reported to be as high as $6-7 \%[8,9]$.

Due to increase in incidences of cesarean section, the incidence of MAP is on rise and thus risk of life-threatening hemorrhage, loss of fertility due to hysterectomy and maternal morbidity [10]. The aim of this case report is to discuss the occurrence of MAP in the absence of prior risk factors in primigravida which is a rare entity.

\section{CASE REPORT}

Here, we present the case of 22 years old, primigravida with no known antenatal risk factors, diagnosed to have placenta accreta intraoperatively. The patient was a booked case at a peripheral hospital and was on regular hematinics and calcium. She was on regular follow-up and did her all ultrasounds whenever she was asked to do so. None of her ultrasound showed any abnormality and apart from minor ailments of pregnancy, the patient did not report to antenatal outpatient department for any comorbid or illness and finally got admitted for delivery as a booked case on reporting spontaneous onset of mild pain abdomen in the afternoon. The patient came into spontaneous labor and progressed normally, that is, according to partographic monitoring and delivered a healthy baby boy vaginally in midnight. After delivery, nursing staff noticed that the patient was continuously bleeding and gynecologist was immediately called upon as the patient did not stop bleeding. The patient had severe postpartum hemorrhage (PPH) after delivery and in spite of all the efforts by the treating gynecologist, that is, exploring of vagina and uterus, suturing of cervical tears, abdominal massaging, all injectable uterotonics and balloon tamponade by Foley's catheter, and bleeding did not stop, she became extremely pale and was shifted to nearest medical college situated $50 \mathrm{~km}$ from this peripheral hospital in view of, no blood bank facility in the hospital, and moreover, she required an urgent hysterectomy.

Medical college was connected by not so good road with super traffic jam at places and stray cattle/dog coming suddenly in the middle of road from nowhere, adding difficulty in maneuvering of ambulance vehicle. The patient was on IV fluids (colloids) and multipara monitor was showing pulse of $146 / \mathrm{min}$ and blood pressure of $76 / 38 \mathrm{mmHg}$ with $\mathrm{SpO}_{2}$ of $88 \%$.

Previously in the labor room while exploring uterus, the anterior uterine wall was not felt properly. It was rough, studded with clots with finger easily penetrating causing more bleeding and gynecologist was asked specifically the nursing staff on duty that "was the placenta expelled completely?" The confident answer from the nurse on duty was "yes sir." (This needs to be asked very distinctly after delivery, from the nursing staff as placenta must be checked thoroughly on expulsion for its completeness as per laid down protocol). 
In the operation theater, she became extremely pale and hemodynamically unstable and total blood loss was estimated to be $3500 \mathrm{ml}$ and was transfused 5 units of cross-matched whole blood, intubated, and started on dual vasopressors. Initial crystalloid and/ or volume therapy may be helpful during the management of acute blood loss, but prompt blood product transfusion is generally needed with heavy bleeding such as that seen at cesarean hysterectomy [11]. Emergency peripartum hysterectomy was done and cause of PPH was found to be "morbidly adherent placenta" which was later proved by histopathological examination of specimen (Fig. 2).

The patient was shifted to intensive care unit on ventilator and was maintaining vitals on single vasopressor. With extreme efforts from the team of doctors, the patient was extubated after $72 \mathrm{~h}$ and shifted to step down ward and later, back to peripheral hospital to take care of her child. She developed fever and wound infection subsequently which was dealt by conservative approach. The patient was later on discharged with a healthy baby after suture removal with hemoglobin of $8.5 \mathrm{~g} \%$.

\section{DISCUSSION}

Morbid adherent placenta is a potentially life-threatening condition. Any prior uterine procedure is a risk factor for morbid adherence of placenta. There has been a marked increase in the incidence of morbid adherent placenta in recent years, mainly attributed to the increased rate of cesarean sections [12].

Our index case, a primigravida with none of the above-mentioned risk factors, gave us a shocking revelation during hysterectomy in operation theater. It is difficult to diagnose such cases antenatally (all

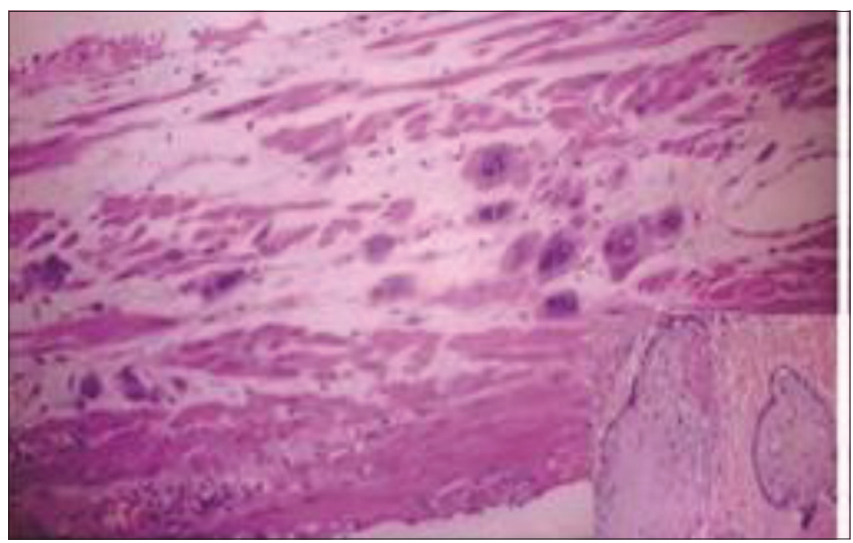

Fig. 1: Microscopic appearance showing transmural trophoblastic infiltration

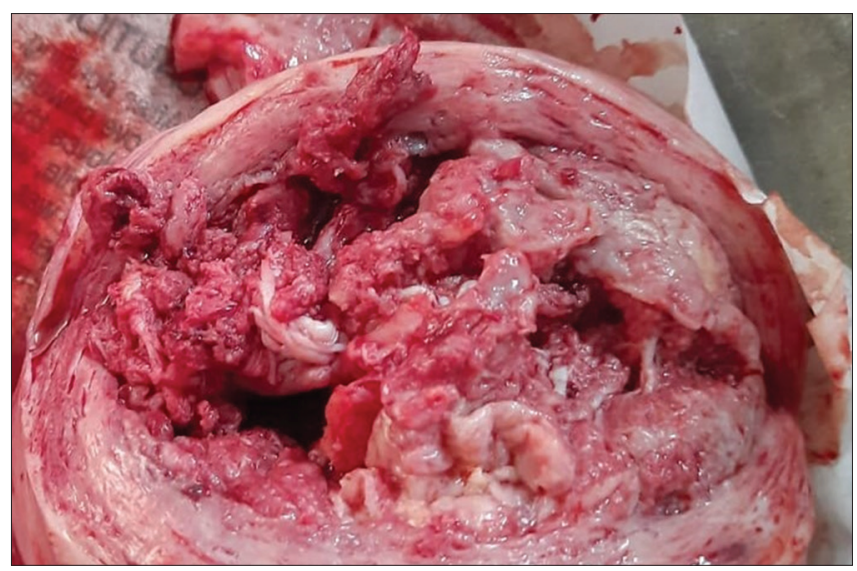

Fig. 2: Histopathological examination showed chorionic villi within myometrium ultrasound reports were normal), given the absence of any antecedent history. By means of specific criteria and ultrasound approach of the presence of bladder line interruption, absence of retroplacental clear zone, and presence of placental lacunae, Comstock et al. [13] were able to, preoperatively, predict MAP with positive predictive value of $48 \%$ with various advantages and disadvantages. Similarly, Shamshirsaz et al. [14] followed multidisciplinary approach in confirmed cases of MAP after delivery by histological examination to have better outcome than compared to non-multidisciplinary approach. While some studies showed reduction of morbidities by means of antenatal ultrasonography [15-17], other studies showed poorer outcome and pre-operative diagnosis didn't much affect the outcome $[18,19]$. Thus, emphasizing the need for standardized diagnostic and treatment strategy for MAP [1]. In our case, being a peripheral set up and being primigravida with no antecedent history, detection through ultrasonography nor any diagnostic multidisciplinary approach was not possible and was followed up as a routine antenatal case.

An in-depth search for articles/case reports for primigravida with placenta accrete was carried out in PubMed and Google Scholar, revealed very few such cases of a primigravida with placenta accrete, being a rare entity. Kuhite et al. [20] reported a case of placenta accrete in primigravida with no risk factors which they managed conservatively by means of injection methotrexate and uterine artery embolization by carefully selecting the patient. In this case, fertility preservation was needed as the child born was extremely premature, low birth weight and had low chances of survival. Similarly, Arnadottir et al. [21] reported a case of placenta increta in primigravida managed conservatively with methotrexate with delivery of healthy infant. Ramalingam and Sahika [22] also reported placenta accreta in primigravida with 28 weeks gestation in which initially conservative management was tried by means of injection methotrexate and bilateral uterine artery embolization, since the patient condition deteriorated, and manual removal of placenta attempt failed, hysterotomy was done and placenta was removed completely. Two more cases of placenta percreta in primigravida were reported by different authors. One case was reported by Kinoshita et al., [23] in Japan with spontaneous rupture of uterus and another case by Rajkumar et al., where cesarean hysterectomy was done in view of massive hemorrhage [24].

A high index of suspicion is needed for accurate antenatal diagnosis of such cases. Antenatal workup helps to plan the management. However, very rarely MAP may be encountered unexpectedly in primigravidae and those without any risk factors. In addition, our patient delivered a healthy baby. Hence, fertility preservation was not a concern in her management and unfortunately, conservative management could not be contemplated as she was hemodynamically very unstable. The standard management for confirmed cases of MAP has been cesarean hysterectomy as described by Fox et al. [25].

\section{CONCLUSION}

Despite the absence of risk factors, MAP can be encountered in primigravida as seen in the above case. MAP in a primigravida presents a tremendous challenge to the obstetrician, when it is not diagnosed antenatally during routine ultrasound, requiring a more sensitive approach with or without fertility preservation, depending on caseto-case basis, as a primary concern. In our case, proactive approach and timely intervention by the obstetric team resulted in saving of a precious life.

\section{CLINICAL SIGNIFICANCE}

It is extremely rare for MAP to occur in a patient with no prior risk factors in a primigravida. Peripartum hysterectomy is the only option in a limited care facility with a hemodynamically unstable patient without a proper full-fledged blood bank facility. It is once again reiterated that bleeding from the vagina that does not slow or stop, drop in blood pressure and signs of shock, that is, blurry vision; having chills, clammy skin or a really fast heartbeat; feeling confused dizzy, sleepy or weak; or 
feeling like you're going to faint are early signs of blood loss and should be looked into with great concern and treating gynecologist should take immediate definitive action.

\section{ACKNOWLEDGMENTS}

I acknowledge and thank to all my coauthors and study participants

\section{AUTHORS' CONTRIBUTIONS}

All authors have contributed to the preparation of manuscript.

\section{CONFLICTS OF INTEREST}

Nil.

\section{AUTHORS' FUNDING}

Nil.

\section{REFERENCES}

1. Fujisaki M, Furukawa S, Maki Y, Oohashi M, Doi K, Sameshima H. Maternal morbidity in women with placenta previa managed with prediction of morbidly adherent placenta by ultrasonography. J Pregnancy 2017;2017:8318751.

2. Hung TH, Shau WY, Hsieh CC, Chiu TH, Hsu JJ, Hsieh TT. Risk factors for placenta accrete. Obstet Gynecol 1999;93:545-50.

3. Wu S, Kocherginsky M, Hibbard JU. Abnormal placentation twentyyear analysis. Am J Obstet Gynecol 2005;192:1458-61.

4. Jacques SM, Qureshi F, Trent VS, Ramirez NC. Placenta accreta mild cases diagnosed by placental examination. Int J Gynecol Pathol 1996; 15:28-33.

5. Chandraharan E, Rao S, BelliAM, Arulkumaran S. The triple-P procedure as a conservative surgical alternative to peripartum hysterectomy for placenta percreta. Int J Gynaecol Obstet 2012;117:191-4.

6. Konijeti R, Rajfer J, Askari A. Placenta percreta and the urologist. Rev Urol 2009;11:173-6.

7. Styron AG, George RB, Allen TK, Peterson-Layne C, Muir HA. Multidisciplinary management of placenta percreta complicated by embolic phenomena. Int J Obstet Anesth 2008;17:262-6.

8. Mathelier AC, Karachorlu K. Placenta previa and accreta complicated by amniotic fluid embolism. Int J Fertil Womens Med 2006;51:28-32.

9. Washecka R, Behling A. Urologic complications of placenta percreta invading the urinary bladder: A case report and review of the literature. Hawaii Med J 2002;61:66-9.
10. O'Brien JM, Barton JR, Donaldson ES. The management of placenta percreta: Conservative and operative strategies. Am J Obstet Gynecol 1996;175:1632-8.

11. Sheikh SM, Khair H. Conservative management of placenta accrete. Isra Med J 2012;4:35-8.

12. Shander A, Goodnough LT. Update on transfusion medicine. Pharmacotherapy 2007;27:57S-68.

13. Committee on Obstetric Practice. ACOG committee opinion. Placenta accreta. Number 266, January 2002. American college of obstetricians and gynecologists. Int J Gynaecol Obstet 2002;77:77-8.

14. Comstock CH, Love JJ Jr., Bronsteen RA, Lee W, Vettraino IM, Huang RR, et al. Sonographic detection of placenta accreta in the second and third trimesters of pregnancy. Am J Obstet Gynecol 2004; $190: 1135-40$

15. Shamshirsaz AA, Fox KA, Salmanian B, Diaz-Arrastia CR, Lee W, Baker BW, et al. Maternal morbidity in patients with morbidly adherent placenta treated with and without a standardized multidisciplinary approach. Am J Obstet Gynecol 2015;212:218.e1-9.

16. Tikkanen M, Paavonen J, Loukovaara M, Stefanovic V. Antenatal diagnosis of placenta accreta leads to reduced blood loss. Acta Obstet Gynecol Scand 2011;90:1140-6.

17. Warshak CR, Ramos GA, Eskander R, Benirschke K, Saenz CC, Kelly TF, et al. Effect of predelivery diagnosis in 99 consecutive cases of placenta accreta. Obstet Gynecol 2010;115:65-9.

18. Eller AG, Porter TT, Soisson P, Silver RM. Optimal management strategies for placenta accreta. BJOG 2009;116:648-54

19. Bailit JL, Grobman WA, Rice MM, Reddy UM, Wapner RJ, Varner MW, et al. Morbidly adherent placenta treatments and outcomes. Obstet Gynecol 2015;125:683-9.

20. Hall T, Wax JR, Lucas FL, Cartin A, Jones M, Pinette MG. Prenatal sonographic diagnosis of placenta accrete-impact on maternal and neonatal outcomes. J Clin Ultrasound 2014;42:449-55.

21. Kuhite H, Mirji S, Shingatgeri S, Shinde G. A rare case of morbidly adherent placenta in a primigravida. World J Anemia 2018;2:74-7.

22. Arnadottir BT, Hardardóttir H, Marvinsdóttir B. Case report seventeen year old primipara with placenta increta treated with methotrexate. Laeknabladid 2008;94:549-52.

23. Ramalingam, Sahika G. A rare placental abnormality in primigravida. Indian J Res 2019;8:562-6.

24. Kinoshita T, Ogawa K, Yasumizu T, Kato J. Spontaneous rupture of the uterus due to placenta percreta at 25-weeks of gestation: A case report. J Obstet Gynaecol Res 1996;22:125-8.

25. Rajkumar B, Kumar N, Sowmya S. Placenta percreta in primigravida, an unsuspected situation. Int J Reprod Contracep Obstet Gynecol 2014;3:239-41. 